\title{
Experimental and Numerical Investigation of Flexural Concrete Wall Design Details
}

\author{
A. Behrouzi ${ }^{1}$; T. Welt ${ }^{2}$; D. Lehman ${ }^{3}$; L. Lowes ${ }^{4}$; J. LaFave ${ }^{5}$; and D. Kuchma ${ }^{6}$
}

${ }^{1}$ Assistant Professor, Dept. of Architectural Engineering, California Polytechnic State Univ. San Luis Obispo, 1 Grand Ave., Bldg. 21, San Luis Obispo, CA 93407. E-mail:

behrouzi@calpoly.edu

${ }^{2}$ Postdoctoral Researcher, 1325 Richelieu Ln, Houston, TX 77018. E-mail: tswelt@gmail.com

${ }^{3}$ Professor, Dept. of Civil and Environmental Engineering, Univ. of Washington, 201 More Hall, Box 352700, Seattle, WA 98195. E-mail: delehman@uw.edu

${ }^{4}$ Professor, Dept. of Civil and Environmental Engineering, Univ. of Washington, 201 More Hall, Box 352700, Seattle, WA 98195. E-mail: lowes@uw.edu

${ }^{5}$ Professor, Associate Head, Dept. of Civil and Environmental Engineering, Univ. of Illinois at Urbana-Champaign, 205 N Mathews Ave., Urbana, IL 61801. E-mail: jlafave@illinois.edu

${ }^{6}$ Professor, Dept. of Civil and Environmental Engineering, Tufts Univ., 200 College Ave., Medford, MA 02155. E-mail: Dan.Kuchma@tufts.edu

\begin{abstract}
Reinforced concrete structural walls are common in mid- to high-rise structures in high seismic regions, and are expected to have good strength and ductility characteristics if designed in accordance with ACI 318-14. However, experimental and analytical investigations of reinforced concrete structural walls and isolated boundary element prisms indicate that the existing design provisions may be insufficient to provide ductile, flexure-dominated response under cyclic loading. Walls designed with an ACI compliant boundary element length are susceptible to shear-compression failures below the maximum ACI allowable shear stress of $10 \mathrm{~A}_{\mathrm{cv}} \sqrt{ } \mathrm{f}_{\mathrm{c}}{ }^{\prime}$. Also of concern is the frequent use of thinner walls in modern design; as the wall's cross-sectional aspect ratio increases, such brittle shear-compression failures occur at even smaller shear stress values. In regards to detailing, special boundary elements with intermediate cross-ties exhibit a minimal improvement in confinement compared to ordinary boundary elements. This response can be linked to inadequacies in multiple code design parameters, including: vertical spacing and area of confinement steel, horizontal spacing and type of restraint to longitudinal bars, and development length provided for transverse reinforcement. Recent in-field wall failures have prompted concerns related to the minimum code required vertical and horizontal web shear reinforcement, as well as the relative amount of vertical-to-horizontal web steel. This paper examines ACI 31814 special boundary element and web reinforcement provisions and provides design recommendations intended to improve wall performance as compared with current ACI requirements.
\end{abstract}




\section{INTRODUCTION}

Many mid- to high-rise reinforced concrete buildings in seismic regions utilize structural walls as a primary lateral-load resisting system. Historically, these walls have performed well in that the damage was moderate (limited to cracking and cover spalling). However, considerable damage to structural wall buildings has been observed in recent earthquakes. This has, to some degree, eroded engineers' confidence in wall performance and current design provisions. There have been notable cases both in New Zealand (2010-11) and in the Chile (2010) earthquakes of significant damage including web or boundary element crushing as well as out-of-plane buckling, especially in flanged walls with thin webs (Figure 1).

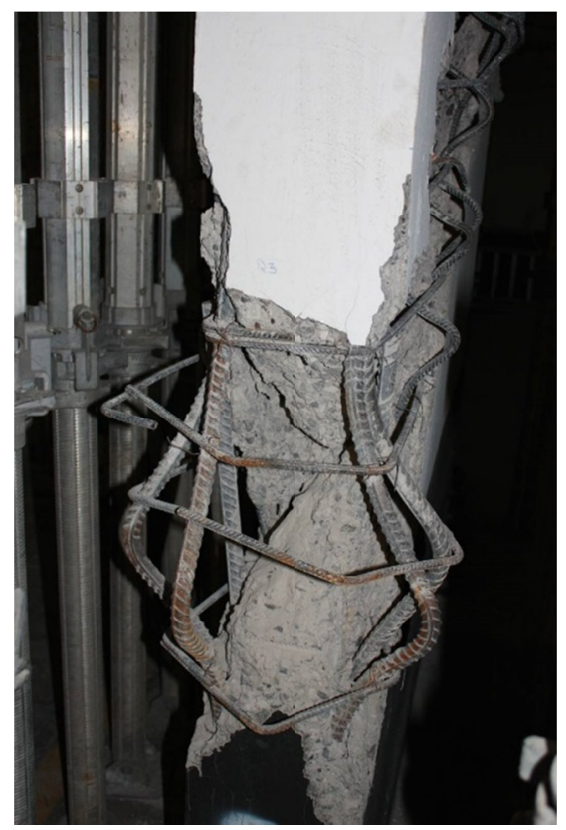

(a)

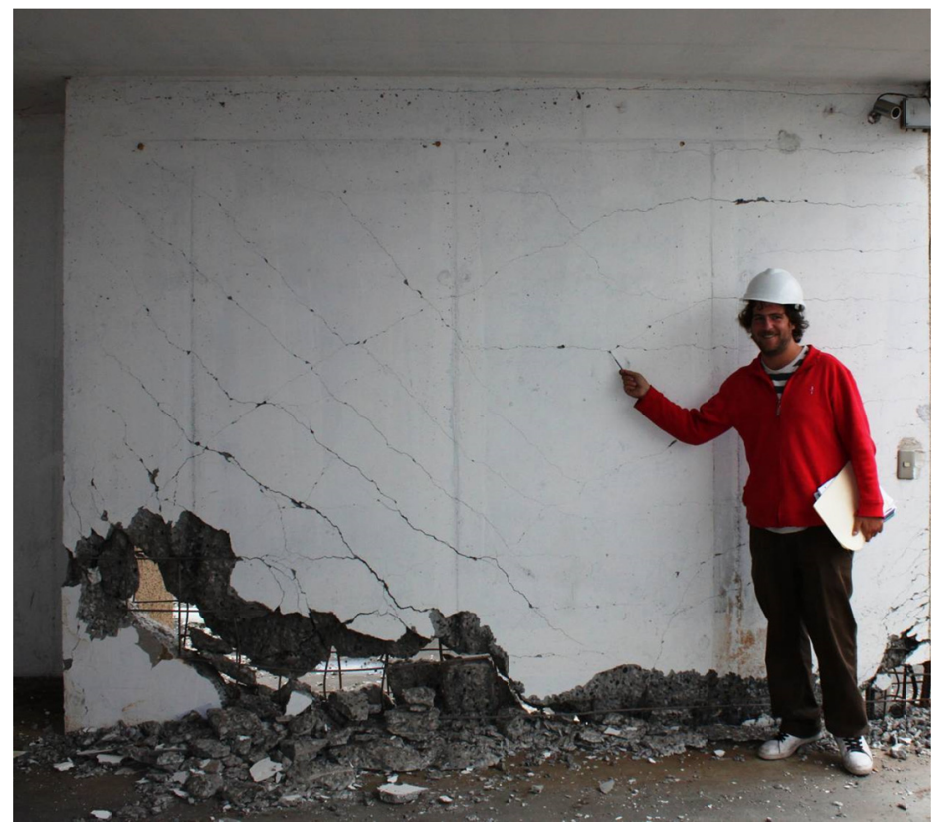

(b)

Figure 1. Damage to: (1) Boundary Element and (b) Wall Web in Chile 2010 (Moehle 2010)

Review of damage from these earthquakes indicated that demand levels, cross sectional shapes, boundary element detailing and other aspects of design require further study (Moehle 2010). The current research was undertaken to examine these issues, which include shear stress demand, web reinforcement, and boundary element confinement. Specifically, these issues were studied in two phases using different research approaches. First, an experimental program was undertaken to examine boundary element detailing through testing of rectangular prisms; the experiments studied spacing of the transverse reinforcement, restraint pattern, and transverse reinforcement ratio as well as type of restraint, in particular studying cross ties and continuous hoops. Second, a computational parametric study (using experimentally validated finite element analyses) was conducted to study the impact of web reinforcement and shear stress demands on the deformability of walls. The results of both the experimental and computational studies are used to develop new design recommendations. 


\section{IMPACT OF BOUNDARY ELEMENT DETAILING: EXPERIMENTAL INVESTIGATION}

The investigation of boundary element details involved analysis of experimental results from rectangular concrete prisms in three test programs by Mander et al. (1988), Massone et al. (2014), and Welt (2015). This database permitted the study of a wide range of values for detailing parameters to determine the impact on normalized peak confined stress $\left(f_{c c^{\prime}} / f_{c}{ }^{\prime}\right)$ and ultimate strain capacity $\left(\varepsilon_{c u}\right)$. The research study was conducted with the aim of developing more rigorous detailing classification levels to improve the confined response of rectangular boundary elements.

\section{VERTICAL SPACING OF TRANSVERSE REINFORCEMENT}

Of all the parameters studied, the vertical spacing of transverse reinforcement was determined to have the most significant effect on the performance of rectangular concrete prisms. Research (e.g., (Rodriguez, Botero, \& Villa, 1999)) indicates that the transverse vertical spacing should not exceed six times the longitudinal bar diameter $\left(6 \boldsymbol{d}_{\boldsymbol{b}}\right)$ to avoid premature buckling of longitudinal reinforcement. Figure 2 shows the relationship of the ratio of vertical spacing of transverse reinforcement-to-longitudinal bar diameter $\left(\boldsymbol{s} / \boldsymbol{d}_{\boldsymbol{b}}\right)$ versus the response metrics of confined stress and strain. Compliant designs near the $6 \boldsymbol{d}_{\boldsymbol{b}}$ vertical spacing limit show only modest improvements in confined stress (approximately $1.25 f_{c}$ ') and strain (less than $1 \%$ ) versus non-compliant designs. These response values are much lower than those expected for a well confined section (Mander et al., 1988). However, if the spacing is reduced to $4 \boldsymbol{d}_{\boldsymbol{b}}$, the stress and strain capacities are greatly increased. This trend is also noted for tests with spacings of $2 \boldsymbol{d}_{\boldsymbol{b}}$ and $3 \boldsymbol{d}_{\boldsymbol{b}}$ (Mander et al., 1988); though reducing the required spacing to these levels may limit constructability.

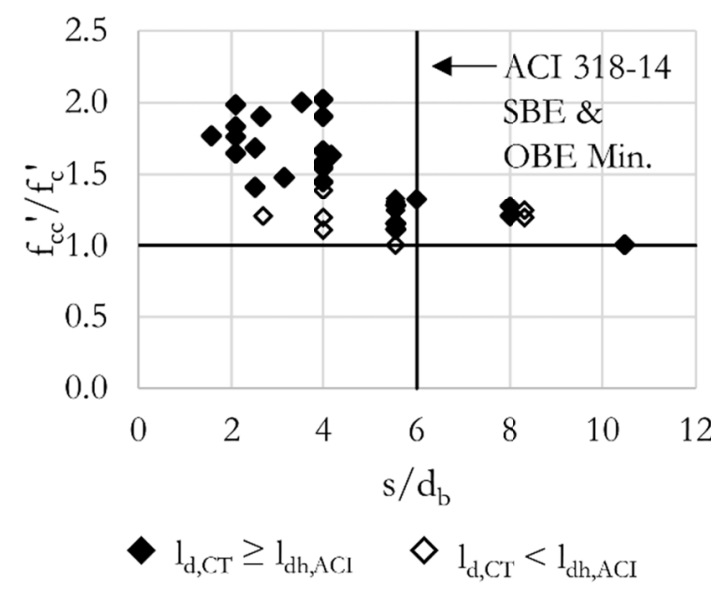

(a)

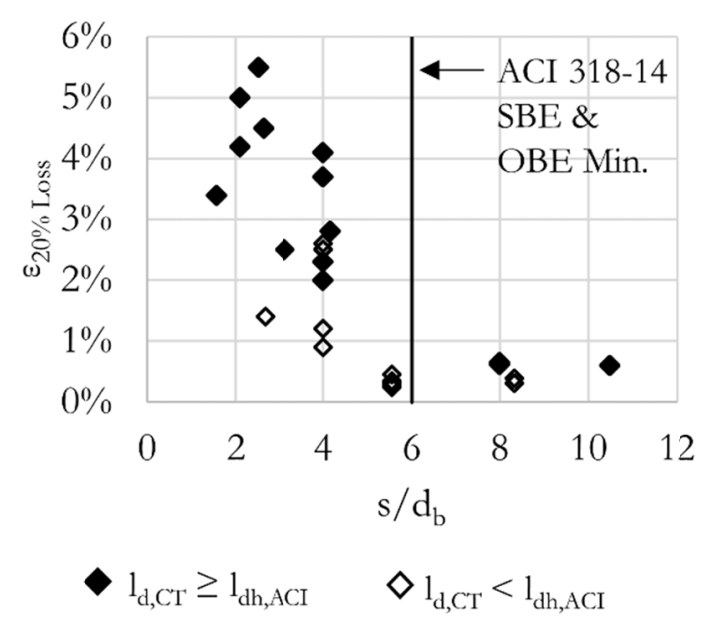

(b)

Figure 2. (a) Stress $\left(f_{c c} / f_{c}\right.$ ') and (b) Strain $\left(\varepsilon_{c u}\right)$ Capacity vs. Vertical Spacing of Confining Steel

\section{VOLUMETRIC TRANSVERSE REINFORCEMENT RATIO}

The volumetric confinement reinforcement ratio $\left(\rho_{t}\right)$ is difficult to modify in isolation such that all other detailing parameters remain constant. In practice, $\rho_{t}$ is typically modified by varying the vertical and/or horizontal spacing of transverse reinforcement. Figure 3 indicates that stress and 
strain capacities are dependent on $\rho_{t}$ and specimens with designs near the ACI318-14 threshold have very low values of $f_{c c}$ and $\varepsilon_{c u}$.

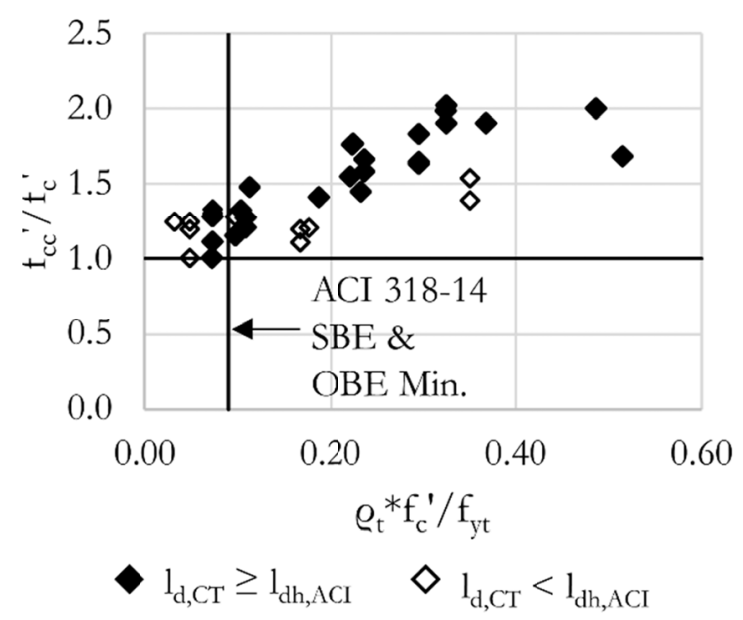

(a)

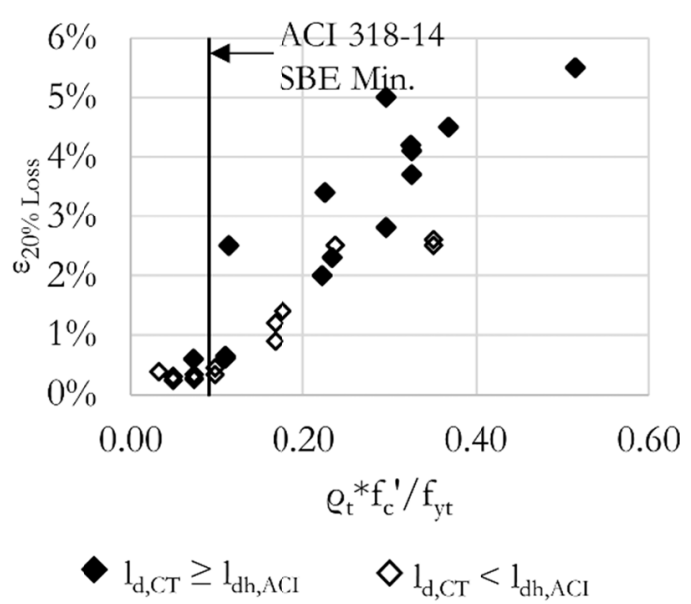

(b)

Figure 3. (a) Stress $\left(\boldsymbol{f}_{c c^{\prime}} / \boldsymbol{f}_{\boldsymbol{c}}\right.$ ') and (b) Strain $\left(\boldsymbol{\varepsilon}_{\boldsymbol{c} u}\right)$ Capacity vs. Volumetric Transverse Reinf. Ratio

\section{CROSS-TIE DEVELOPMENT LENGTH}

Reinforcing bars are detailed to ensure the bar can develop the yield strength, at a minimum. For hooked bars (cross-ties fall into this category), the bar length must be $\boldsymbol{l}_{\boldsymbol{d h}}$ or greater; however, there is no explicit requirement that cross-ties be fully developed. To study the effect of crossties that do not meet the ACI318-14 minimum development length, the experimental test data were divided into two categories: $\boldsymbol{l}_{\boldsymbol{d}, \boldsymbol{C} \boldsymbol{T}}<\boldsymbol{l}_{\boldsymbol{d} \boldsymbol{h}, \boldsymbol{A C I}}$ and $\boldsymbol{l}_{\boldsymbol{d}, \boldsymbol{C T}}>\boldsymbol{l}_{\boldsymbol{d h}, \boldsymbol{A C I}}$ (open versus solid markers in Figures 2-3, respectively). The results clearly show that fully developed cross-ties enhance the response of rectangular reinforced concrete prisms. Figure 4 depicts (i) the idealized demand and (ii) damage to the cross-ties with insufficient development length. Figure 4(b) illustrates how hooks open after cover spalling which results in a dramatic reduction in the confining effect of the cross-ties.

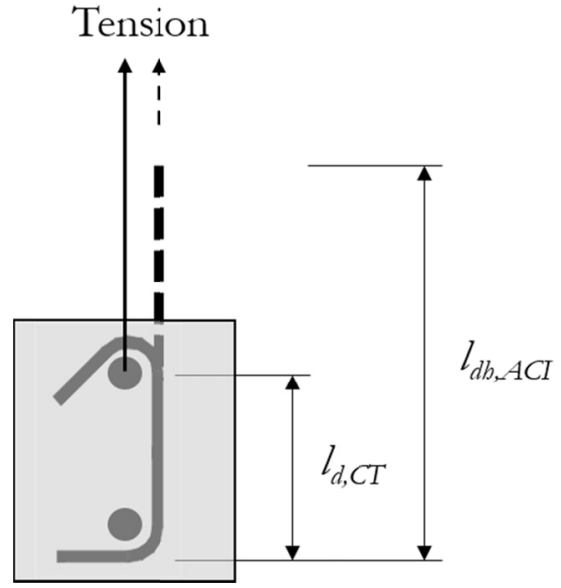

(a) Idealized Response

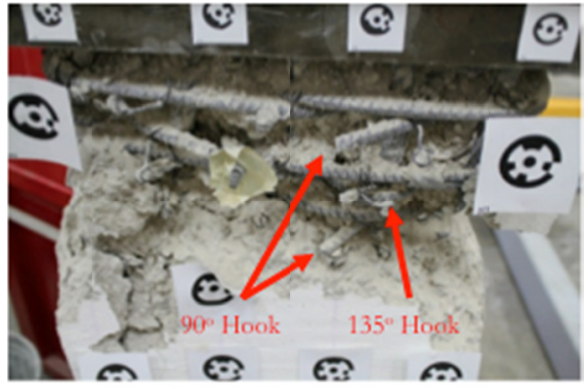

(b) Opening of $90^{\circ}$ Hooks (Welt 2015)

Figure 4. Response of Crossties with Inadequate Development Length $\left(\boldsymbol{l}_{\boldsymbol{d}, \boldsymbol{C T}}<\boldsymbol{l}_{\boldsymbol{h d}, \boldsymbol{A C I}}\right)$ 


\section{PATTERN OF LONGITUDINAL BAR RESTRAINT}

The experimental results of rectangular prism tests by Welt (2015) and Massone et al. (2014) indicated that restraining each longitudinal bar improved compressive response. Figure 5 shows the relationship of bar restraint to the response metrics of confined stress and strain. These plots include only specimens with adequate development and are subdivided into three categories: (i) all bars restrained and $s<3 \boldsymbol{d}_{b}$, (ii) all bars restrained and $\mathrm{s}=4 \boldsymbol{d}_{\boldsymbol{b}}$, and (iii) alternate bars restrained and $s=4 d_{b}$. All three categories of specimens were able to achieve a strain capacity at or in excess of $2 \%$, a value much larger than the specimens with inadequate development or widely spaced cross-ties. Examination of test prisms with $\mathrm{s}=4 \boldsymbol{d}_{\boldsymbol{b}}$ indicated that specimens with alternate bar restraint exhibit lower stress and strain capacities than those with each bar restrained. Though the pattern of bar restraint does impact compressive response, it is less significant than the effects of boundary element detailing parameters of vertical spacing or development length.

\section{HORIZONTAL SPACING OF TRANSVERSE REINFORCEMENT}

Based on ACI 318-14, horizontal spacing of the confining reinforcement $\left(\boldsymbol{h}_{\boldsymbol{x}}\right)$ must be no more than 14 in. Figure 5 assesses this $\boldsymbol{h}_{\boldsymbol{x}}$ limit using the experimental data by scaling specimen spacing to a full-scale wall by a multiplier of 12 in. divided by the wall thickness (12-in./b). This conversion assumes a full-scale wall to be 12 in thick. While none of the specimens were detailed for the ACI limit of $\boldsymbol{h}_{\boldsymbol{x}}=\mathbf{1 4}$, specimens with reduced $\boldsymbol{h}_{\boldsymbol{x}}$ values exhibit an improved confinement capacity. There is an additional horizontal bar spacing limit in ACI318-14 that specifies the maximum distance between restrained longitudinal horizontal as $2 \boldsymbol{b} / 3$. Examination of Figure 5 indicates that this horizontal spacing ( $2 \boldsymbol{b} / 3$ corresponding to $\left.\boldsymbol{h}_{\boldsymbol{x}}=\boldsymbol{8}\right)$ is adequate as it results in a peak stress at or in excess of 1.5 times the unconfined stress and a strain capacity of at least $2.0 \%$.

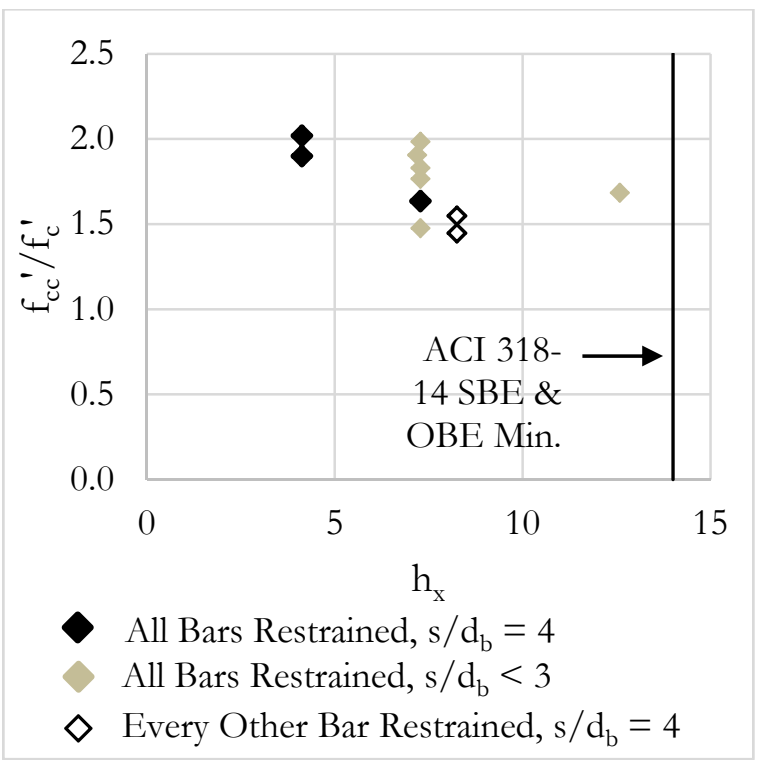

(a)

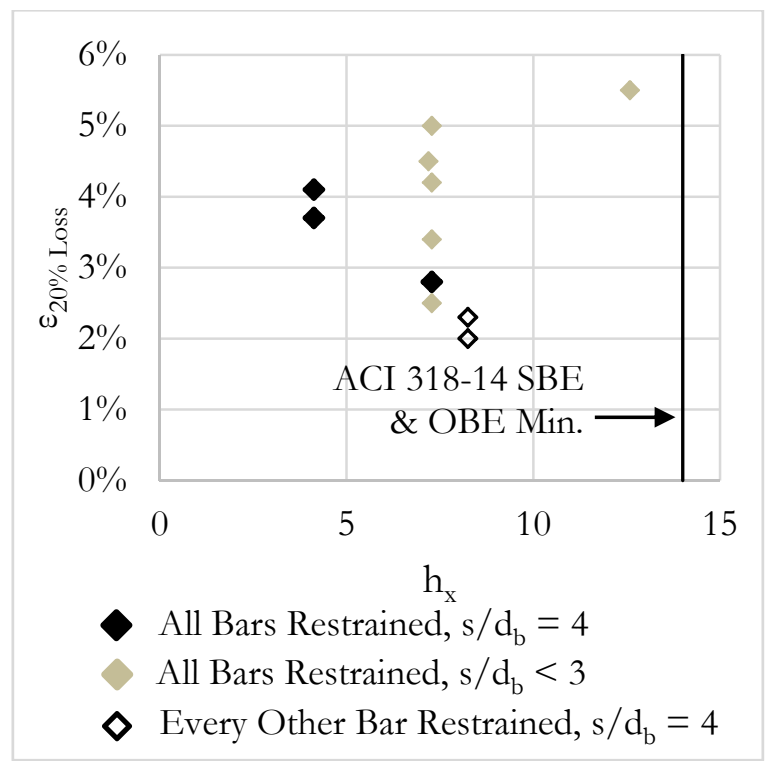

(b)

Figure 5. Stress $\left(f_{c c^{\prime}} / f_{c}{ }^{\prime}\right)$ and Strain $\left(\varepsilon_{c u}\right)$ Capacity vs. Pattern of Bar Restraint and Horizontal Spacing 


\section{IMPACT OF SHEAR STRESS AND WEB REINFORCEMENT ON DUCTILITY OF WALLS: ANALYTICAL INVESTIGATION}

Review of prior experimental and in-field performance of both planar and non-planar reinforced concrete wall configurations shows that, rather than the expected flexural mode dominated by tensile response, there are many occurrences where compression failures are observed in the boundary element and/or web of walls. In order to more extensively examine the design parameters that impact the deformability of walls a computational parametric study was undertaken using the ATENA 3D software developed by Cervenka Consulting (http://www.cervenka.cz) which is a high-resolution, non-linear finite element analysis tool that employs three-dimensional elements and is specifically designed for simulating the response of reinforced concrete structures. The following sections of the paper describe the process conducted by Whitman (2015) in order to validate the ATENA 3D numerical modelling approach against existing experimental wall test results, followed by a discussion of the findings for a selection of design parameters investigated in the study including the impact of shear stress demand, cross-sectional aspect ratio, boundary element length, and web reinforcement ratios on wall deformation and ductility.

\section{VALIDATION OF NUMERICAL MODEL}

Whitman (2015) utilized eight (8) experimentally-tested slender planar reinforced concrete walls subjected to a quasi-static cyclic loading in order to calibrate the numerical model in ATENA 3D. Each of the walls exhibited flexural-compression type failures; this was intentional as the objective of the remainder of the parametric study was to investigate walls with significant compressive damage. The eight walls represented a range of axial load and cross-sectional aspect ratios as well as shear stress demands. The calibration process focused on selection of concrete and steel material constitutive modelling parameters, percentage of longitudinal and confinement steel represented as smeared versus discrete reinforcing bars, and mesh discretization. The objective with the calibration was to accurately simulate the measured strength, stiffness, drift capacity, ductility, and failure mode of the walls.

Subsequent to the calibration, Whitman (2015) was able to successfully simulate a set of nineteen (19) slender planar wall tests. Table 1 summarizes the statistics for the ratio of simulated-to- measured values for stiffness, maximum strength and displacement at onset of strength loss for these simulated wall specimens. Figure $\mathbf{6}$ shows simulated and measured loaddeformation response for select walls. In all cases, the drift corresponding to loss of lateral load carrying capacity was correctly simulated.

Table 1. Statistics for Ratio of Simulated to Measured Response Quantities

\begin{tabular}{|c|c|c|c|}
\hline & Yield Stiffness & Max. Strength & Displacement \\
\hline Median & 0.91 & 0.99 & 0.98 \\
\hline Coefficient of Variation & 0.29 & 0.05 & 0.06 \\
\hline
\end{tabular}

Using the validated finite element model, Whitman (2015) conducted a parametric study to investigate the impact of various design parameters on the response of planar flexure-controlled walls. Whitman found that for planar walls, drift capacity and failure mode depends on: (i) the 
shear demand, (ii) the cross-sectional aspect ratio of the wall (CSAR $=\boldsymbol{l}_{w} / \boldsymbol{b}$, i.e., the length of the wall, $\boldsymbol{l}_{\boldsymbol{w}}$, divided by the width of the wall, $\boldsymbol{b}$ ) and (iii) the length of the boundary element, $\boldsymbol{l}_{\boldsymbol{b} e}$, relative to the neutral axis depth, $\boldsymbol{c}$.

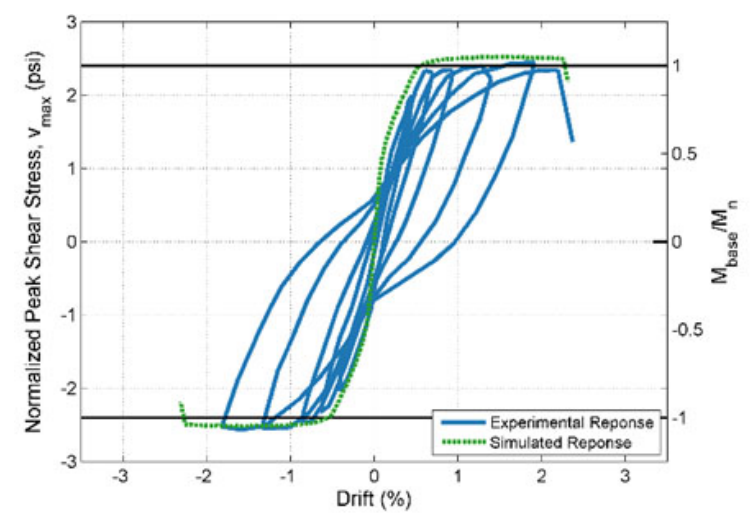

(a) RW1 (Wallace and Thompson, 1995)

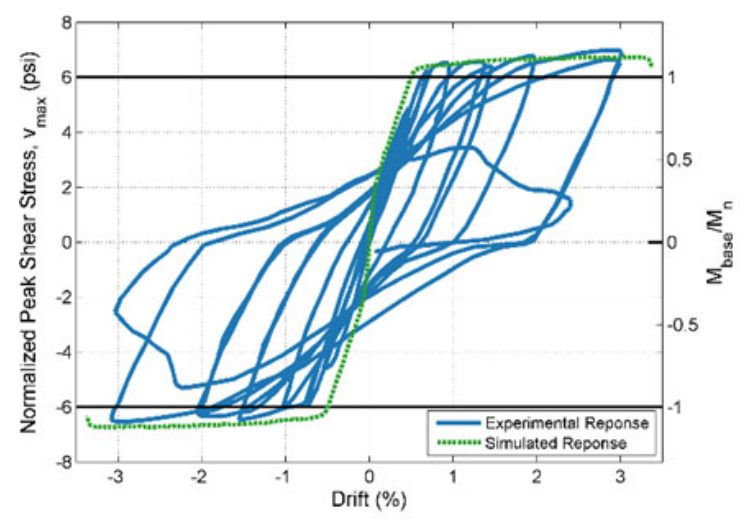

(c) RW-A20-P10-S63 (Tran 2012)

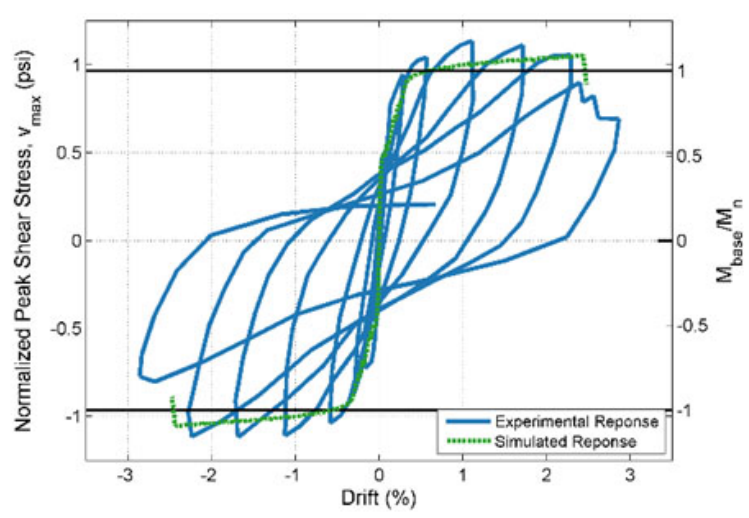

(b) R1 (Oesterle et al., 1975)

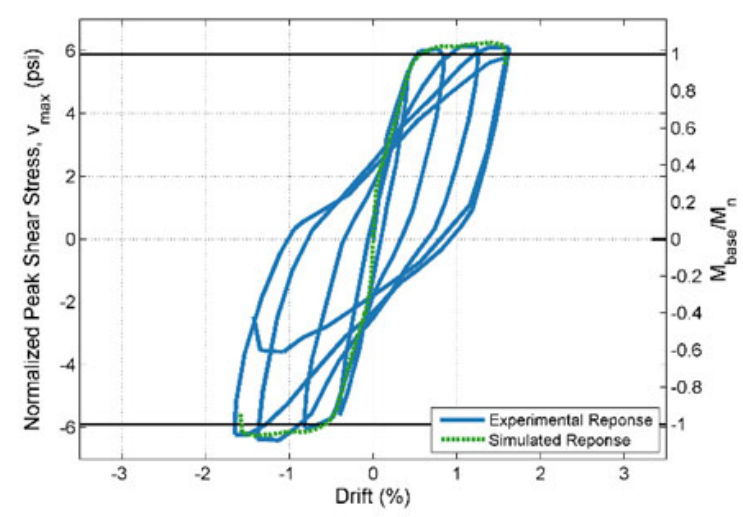

(d) S6 (Vallenas et al., 1979)

Figure 6. Simulated and measured response histories for planar walls (Whitman 2015)

\section{IMPACT OF SHEAR STRESS DEMAND AND BOUNDARY ELEMENT LENGTH}

The impact of shear stress demand and CSAR on the minimum principal stress distribution is illustrated in Figures $\mathbf{7}$ and $\mathbf{8}$, respectively. In both figures, the simulated stress contours from ATENA 3D are shown for loads corresponding to: (i) nominal flexural strength $\left(\boldsymbol{M}_{\text {base }} / \boldsymbol{M}_{\boldsymbol{n}}=1\right)$, (ii) a displacement demand halfway between nominal flexural strength and the point at which strength loss initiated, and (iii) the point at which lateral strength loss initiated (designated as "Failure" in the figures).

The wall specimens in Figure 7 have nearly identical cross-sectional aspect ratios of approximately 20 , which is similar to that found in modern construction (e.g., a CSAR $=20$ would be equivalent to an 18-in thick by 30 -foot long wall). The wall shown in Figure 7a was subjected to a low shear stress demand of $1.1 \sqrt{ } \boldsymbol{f}_{\boldsymbol{c}}{ }^{\prime} \boldsymbol{A}_{\boldsymbol{g}}$ (with $\boldsymbol{f}_{\boldsymbol{c}}{ }^{\prime}$ in psi) and fails due to longitudinal bar rupture (BR failure) based on the failure classification procedure described in Whitman (2015). There does not seem to be a notable change in the minimum principal stress prior to and at failure. 
High minimum principal stresses are able to be contained within the boundary element, rather than the boundary element losing compressive strength and these demands transferring to the wall web. In contrast, the wall shown in Figure $7 \mathrm{~b}$ was subjected to a relatively high shear stress

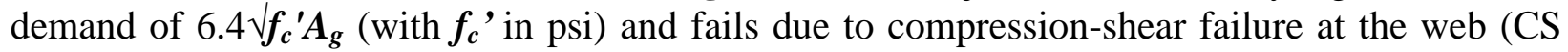
failure). The minimum principal stress contours in Figure $7 \mathrm{~b}$ are distinct from those in Figure $7 \mathrm{a}$ and show significant variation with increasing drift demand. The higher shear stress demand on this wall results in more heavily-loaded, diagonal compression struts spanning from the tension region near the top of the wall to the compressive region at the base of the wall and results in a region of high compressive demands along the base of the wall. There are high minimum principal stress values within and outside of the boundary region, which indicates that there is significant compressive demand on the wall web. A compression-shear failure initiates at the web-boundary element interface where concrete crushing is observed, this reduction in compressive capacity is apparent in the stress contours at the base of the wall in the boundary element as they progress from green in the $\boldsymbol{M}_{\text {base }} \boldsymbol{M}_{\boldsymbol{n}}=1$ image to yellow and finally red at failure.

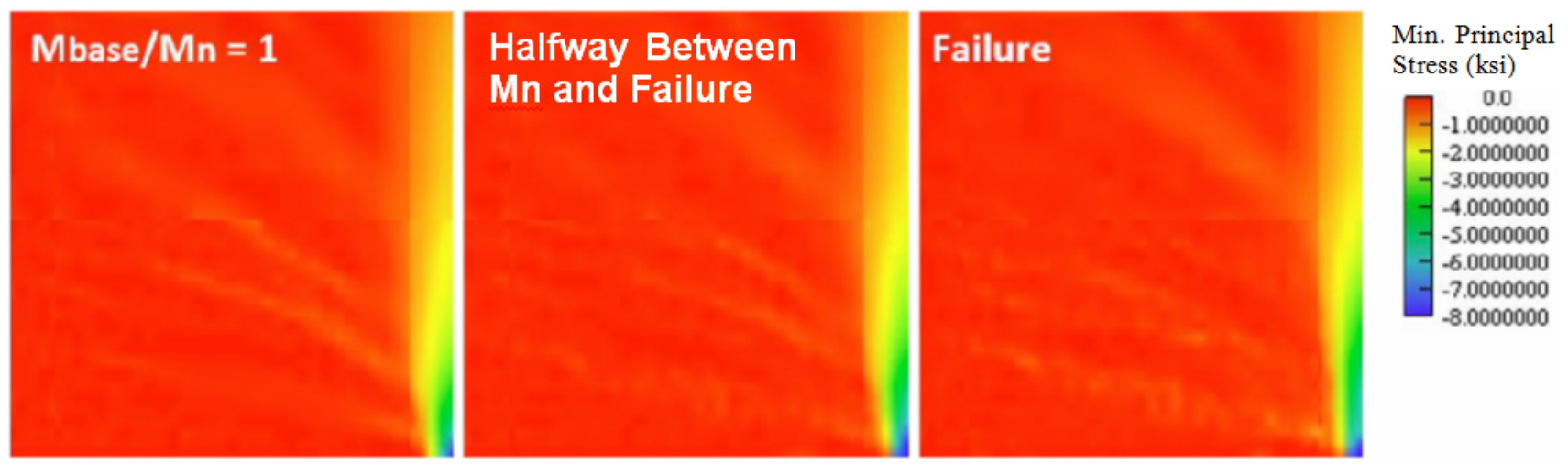

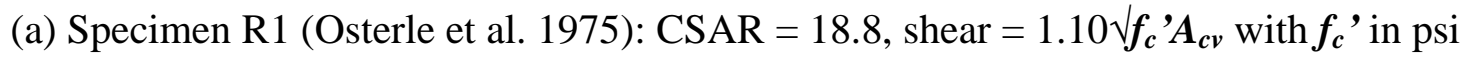
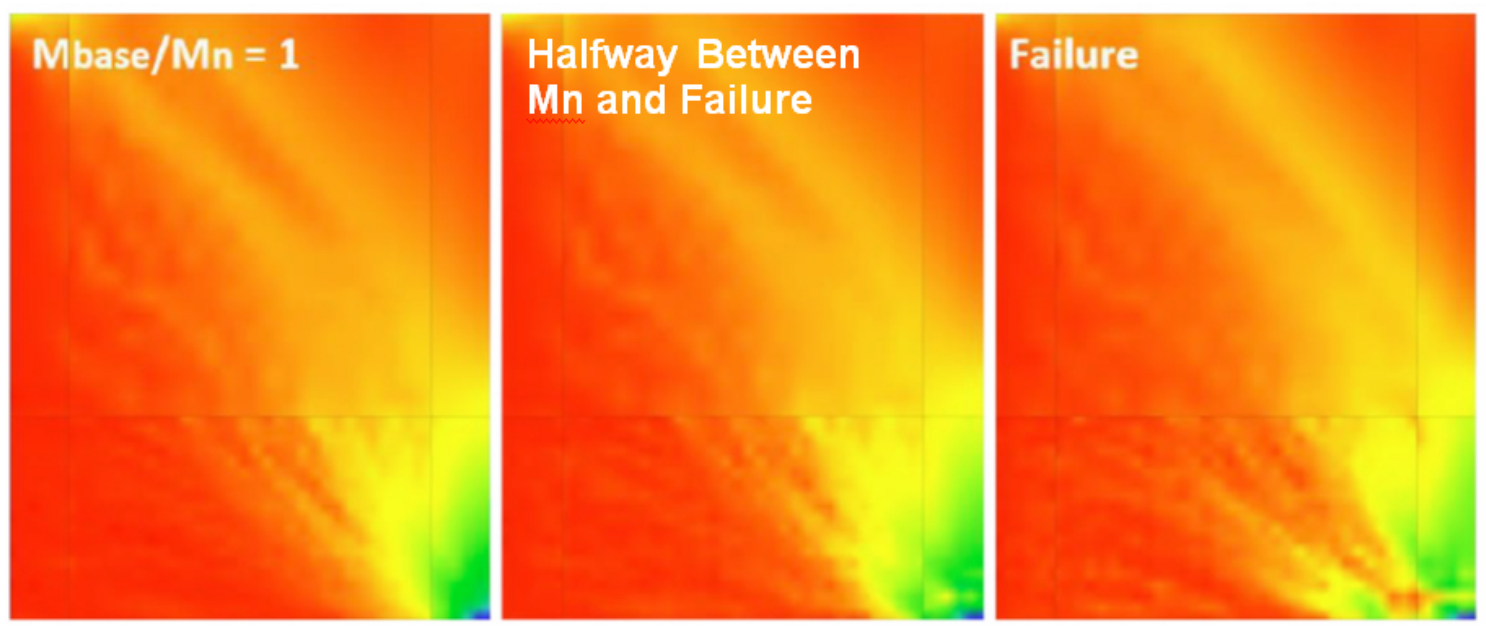

Min. Principal Stress (ksi)

0.0 $-1.2500000$ $-2.5000000$ $-3.7500000$ $-5.0000000$ $-6.2500000$ $-7.5000000$ $-8.7500000$ $-10.000000$

(b) Specimen S6 (Vallenas et al. 1979): CSAR $=21.1$, shear $=6.42 \sqrt{f_{c}} \boldsymbol{A}_{\boldsymbol{c} v}$ with $\boldsymbol{f}_{\boldsymbol{c}}{ }^{\prime}$ in psi

Figure 7. Minimum principal stress contours for $\mathrm{RC}$ wall specimens with approximately the same CSAR and different shear stress demands 
Figure 8 shows the impact of cross-sectional aspect ratio. The two simulated walls have approximately the same shear stress demand $\left(\sim 6 \sqrt{ } f_{c}{ }^{\prime}\right)$ but different cross-sectional aspect ratios; the wall in Figure 8a has CSAR $=8$, while the wall in Figure 8b has CSAR $=21$. For the low CSAR wall, high stresses are predominately contained within the boundary element and concrete degradation also occurs exclusively in this confined region; the high CSAR wall has high stresses extending outside of the boundary element into the unconfined wall web and exhibits concrete crushing which initiates at the web-boundary element interface. This results suggest that walls subject to relatively high shear stress demands fail in a more brittle manner if the corresponding CSAR ratio is high and the boundary element is not able to sustain the high compressive demands such that the wall web is also heavily stressed.
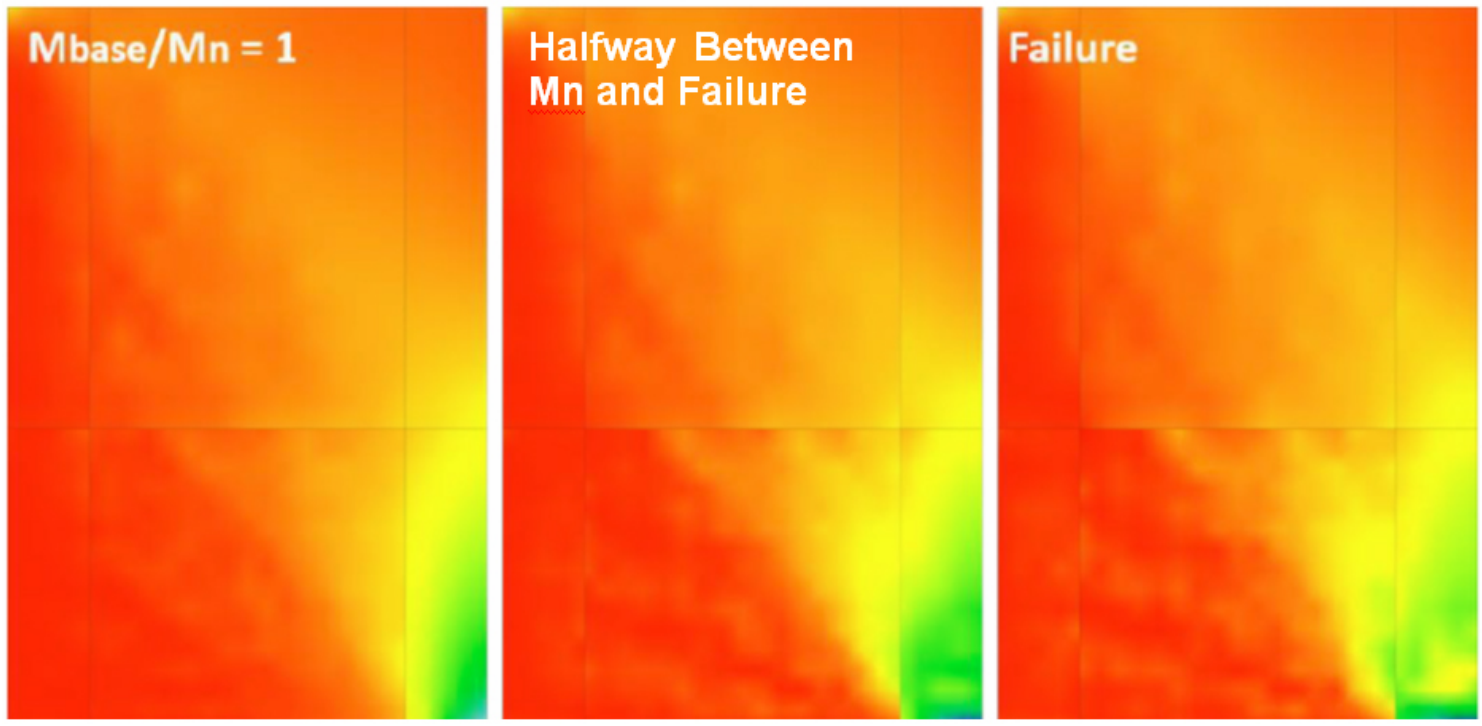

Min. Principal Stress (ksi)

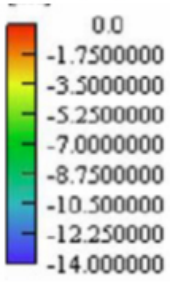

(a) Specimen RW-A20-P10-S63 (Tran 2012): CSAR $=8.0$, shear $=6.10 \sqrt{ } f_{c}{ }^{\prime} \boldsymbol{A}_{c \boldsymbol{v}}$ with $\boldsymbol{f}_{\boldsymbol{c}}$ ' in psi
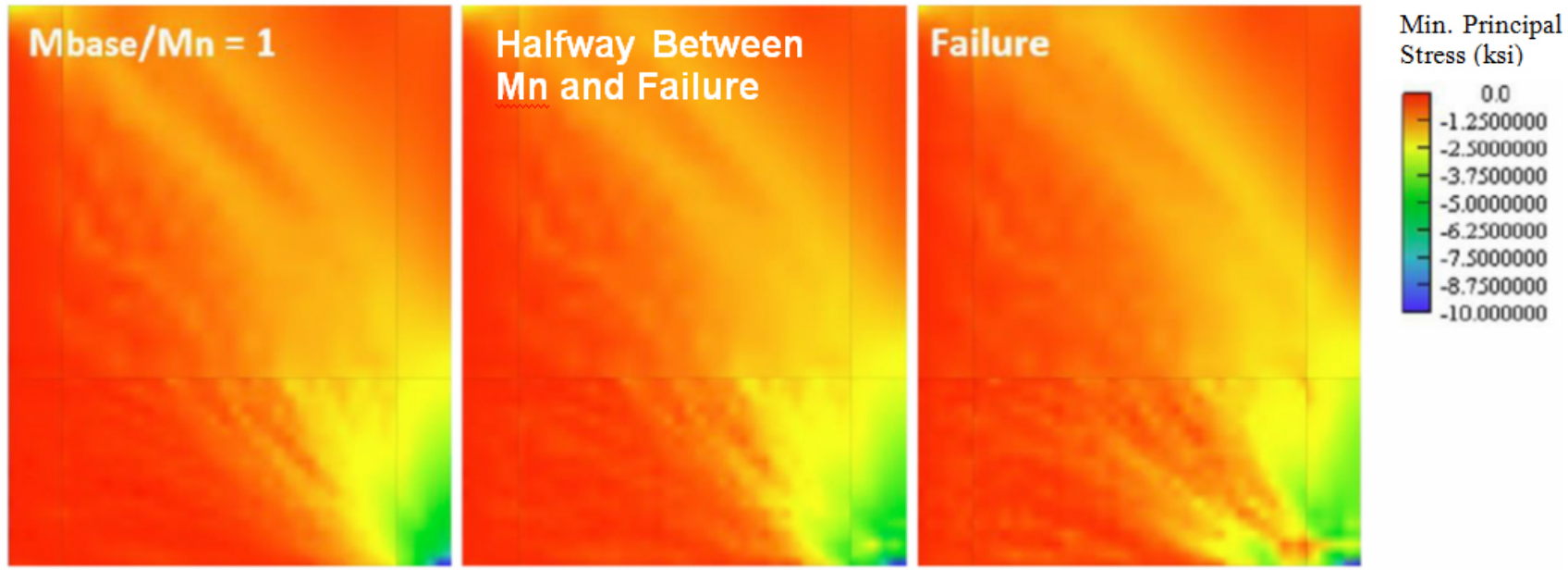

(b) Specimen S6 (Vallenas et al. 1979): CSAR $=21.1$, shear $=6.42 \sqrt{f_{c}}{ }^{\prime} \boldsymbol{A}_{c v}$ with $f_{c}$ ' in psi

Figure 8. Minimum principal stress contours for $\mathrm{RC}$ wall specimens with approximately the same shear stress and different CSARs 
For walls with sufficient shear strength in order to achieve flexural-dominated response, the failure mode can be classified as: (i) bar rupture (BR) as shown in Figure 7a, (ii) compressive failure in the boundary element (CB) as shown in Figure 8a, or (3) compressive-shear (CS) failure in the web adjacent to the boundary element as a result of the shear stresses, as shown in Figure $7 \mathrm{~b}$ and Figure 8b. Figure 9 includes fragility curves that describe the drift corresponding to probability of wall failure for each of the three failure modes. It is clear that walls with a CS failure mode have much lower drift capacities than walls that fail in BR or CB modes.

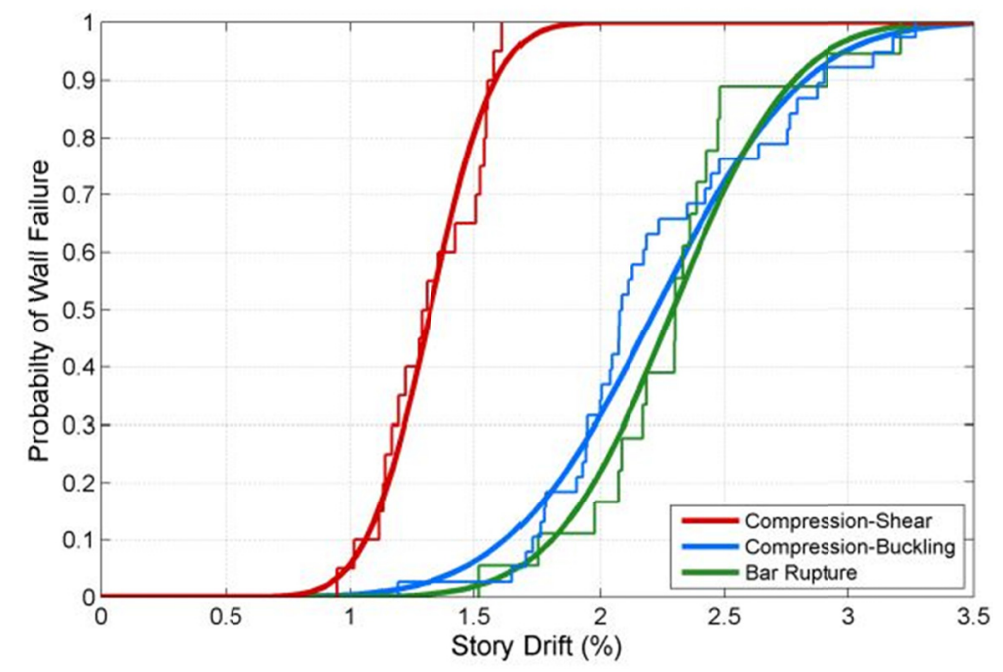

Figure 9. Fragility Curves for Different Wall Failure Modes

The data that has been presented for the parametric thus far show that the CS failure mode is a result of the high minimum principal stresses outside of the boundary element. To explore the impact of the boundary element length on the failure mode and drift capacity of walls, a parametric study was undertaken. Three reference models with different confined boundary element length-to-wall-length $\left(\boldsymbol{l}_{\boldsymbol{B} E} / \boldsymbol{l}_{\boldsymbol{w}}\right)$ were developed; these reference models investigated walls with $\boldsymbol{l}_{\boldsymbol{B} E}$ in excess of the ACI minimum confined boundary element length of $\boldsymbol{c} / 2$ and $\boldsymbol{c}-\boldsymbol{0 . 1 \boldsymbol { l } _ { \boldsymbol { w } }}$. The length of the boundary element and shear stress demand were then varied for the remaining models. In all, thirty (30) additional wall simulations were developed in ATENA 3D.

Figure 10 summarizes the results of the parametric study related to boundary element length. Figure 10a plots the failure mode as a function of shear stress demand and normalized boundary element length $\left(\boldsymbol{l}_{\boldsymbol{B} E} / \boldsymbol{c}\right)$ where $\mathrm{CSAR}=20$ (compression-shear failures are of considerable concern for walls with higher CSAR ratios). For walls with a confined boundary element length $\left(\boldsymbol{l}_{\boldsymbol{B} E}\right)$ less than the neutral axis depth at nominal strength, $\boldsymbol{c}$, and moderate to high levels of shear stress demand (4-8 $\sqrt{ } f_{c}$ ' psi), failure resulted from crushing of the web and boundary element, as indicated by the red markers associated with CS failure. However, walls where the full compression depth $(\boldsymbol{c})$ was confined sustained a CB or BR failure CS which results in larger drift capacities, as indicated by Figure $10 \mathrm{~b}$.

Figure 10b plots the drift capacity for selected simulated (circular marker) and experimental (diamond marker) walls. The results show that (1) the tested walls have large confined lengths, in excess of $0.8 \boldsymbol{l}_{\boldsymbol{B} \boldsymbol{E}}$, and (2) increasing the confined length increases the drift capacity for walls of 
a given length (note that each color represents a single wall length with the confined length and shear stress varied).

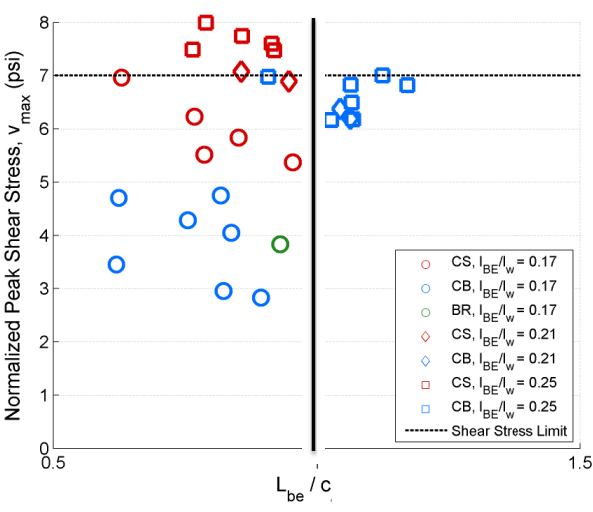

(a)

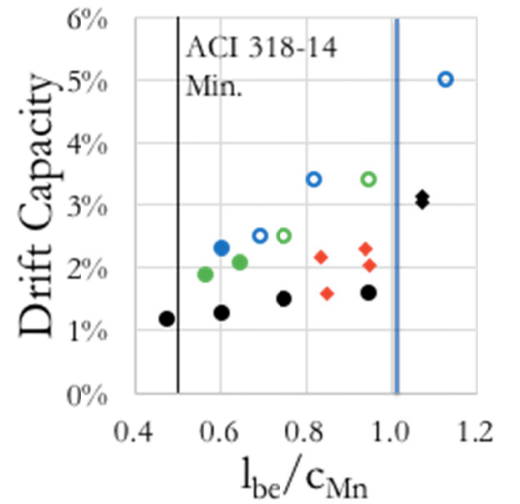

(b)
- Experimental-L0

- Experimental-L1

- Simulated-L1 (CB)

- Simulated-L2 (CB)

- Simulated-L2 (BR)

- Simulated-L.3 (CB)

○ Simulated-L3 (BR)

BR - Bar Rupture Failure $\mathrm{CB}$ - Crushing Failure

Figure 10. Impact of (a) Boundary Element Length on Failure Mode and (b) Drift Capacity

An expanded investigation into the impact of boundary element length was undertaken in Behrouzi (2016) with a CSAR $\approx 20$. Figure 11 is a bar chart indicating the percent difference in drift and displacement ductility that results from increasing the boundary element length from ACI compliant to the full neutral axis depth, $c$. These results are categorized based on specific shear stress demand level of 4.5, 6.0, and $9.0 \sqrt{ } f_{c} \boldsymbol{A}_{c v}$. This figure indicates that "extended" boundary element walls generally have a better response for deformation and ductility strength metrics than walls with an ACI compliant boundary element length. Increasing the length of the boundary element to the full neutral axis appears to have modest benefits in terms of drift capacity at an average of $8 \%$ improvement. For the deformation and ductility metrics, it appears

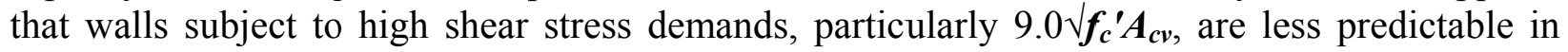
their response possibly due to the brittle nature of these walls.
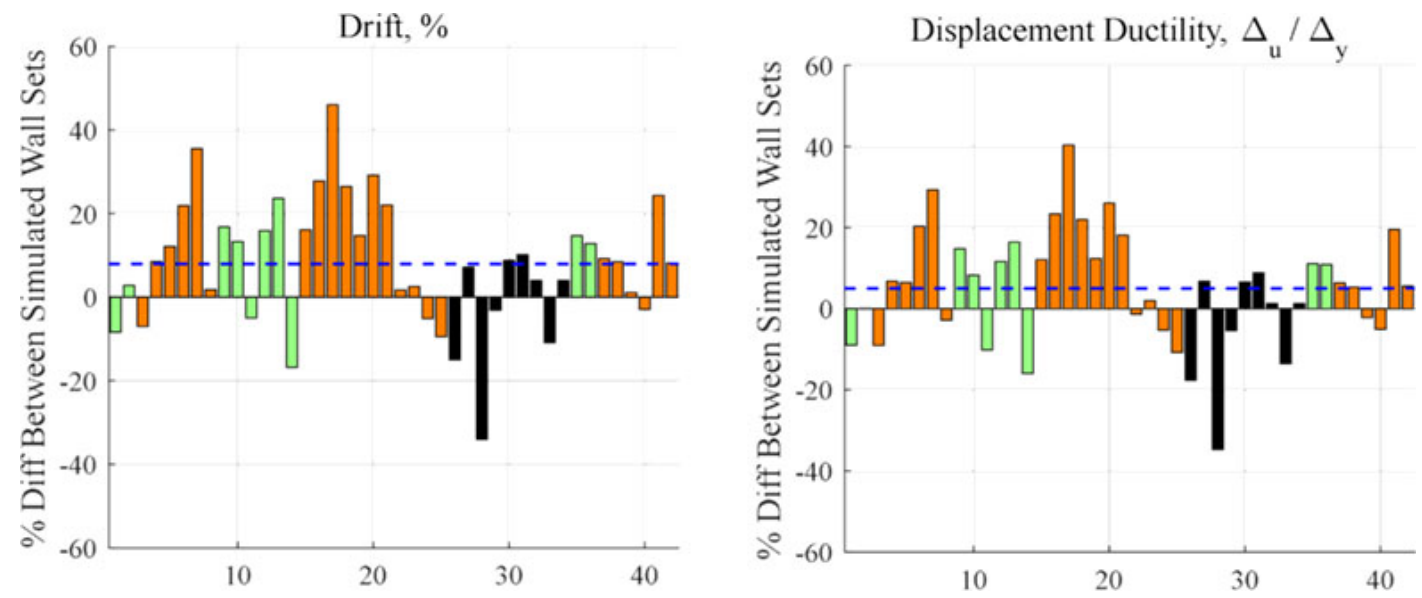

Figure 11. Impact of Confined Length of Drift Capacity and Ductility

\section{IMPACT OF WEB REINFORCEMENT}

The minimum web reinforcement ratios in $\mathrm{RC}$ walls precedes the advent of modern seismic design. At present, the minimum distributed web (or shear) reinforcement ratio for special 
structural walls in both the vertical and horizontal directions is 0.0025 , and has been since the introduction of seismic design provisions for walls in ACI318-71. Unassociated with specific seismic design provisions, the 0.0025 value first appeared in the 1910 NACU Standard as the minimum total reinforcement ratio required for a wall. The only notable exceptions that occur between 1910 and 1971 for the total reinforcement ratio are in 1920 (where no explicit minimum reinforcement ratio was provided for walls), as well as 1956 and 1963 (where vertical reinforcement ratio minimum was reduced to 0.0015 , though the horizontal ratio remained 0.0025). This historic timeline shows that the minimum web reinforcement ratio values used today are rooted in pre-seismic requirements from over a hundred years ago.

The shear design requirements have also evolved very little over time since the formal inclusion of seismic provisions in ACI 318-71. Originally shear capacity was calculated $\boldsymbol{\varphi} \boldsymbol{V}_{\boldsymbol{n}}=\boldsymbol{\varphi}\left(\boldsymbol{V}_{\boldsymbol{c}}+\boldsymbol{V}_{\boldsymbol{s}}\right)$ where $\boldsymbol{V}_{\boldsymbol{c}}=2\left({ }_{\boldsymbol{f}_{c}}{ }^{\prime} \boldsymbol{b} \boldsymbol{d}\right)$ and $\boldsymbol{V}_{\boldsymbol{s}}=\left(\boldsymbol{A}_{\boldsymbol{v}, \boldsymbol{h}} \boldsymbol{f}_{\boldsymbol{y}} \boldsymbol{d} / \boldsymbol{s}_{2}\right.$. This changed in ACI 318-83 when the code became more consistent with the current approach of calculating $\boldsymbol{V}_{\boldsymbol{n}}=\boldsymbol{A}_{\boldsymbol{c} v}\left(\boldsymbol{\alpha}_{\boldsymbol{c}} \sqrt{ } \boldsymbol{f}_{\boldsymbol{c}}{ }^{\prime}+\boldsymbol{\rho}_{\boldsymbol{v}, \boldsymbol{h}} \boldsymbol{f}_{\boldsymbol{y}}\right)$, where, $\boldsymbol{h}_{\boldsymbol{w}} / \boldsymbol{l}_{\boldsymbol{w}} \geq$ $1.5 \rightarrow \boldsymbol{\alpha}_{c}=3.0, \boldsymbol{h}_{w} / \boldsymbol{l}_{\boldsymbol{w}} \geq 2.0 \rightarrow \boldsymbol{\alpha}_{c}=2.0$, and varied linearly in between these values. The maximum shear limit on an individual wall has been $\boldsymbol{V}_{\boldsymbol{n}} \leq 10 \sqrt{\boldsymbol{f}_{c}} \boldsymbol{A}_{\boldsymbol{c} v}$ since ACI 318-71. Note that there were some changes in language or variable designations in these expressions, but the intent of these code provisions have not changed for the last 30-40 years.

The impact of increasing the web reinforcement beyond the ACI minimum (beyond what is required to resist shear) has not been studied. In addition, significant earthquake damage is sustained by lightly reinforced concrete walls, leading to early web reinforcement fracture. However, there are limited existing experimental test data related to the response of slender walls with varying vertical and/or horizontal web reinforcement ratios. A parametric study was conducted using the modeling approach described above to study the impact of shear stress demand coupled with web reinforcement on the ductility of planar walls.

The slender concrete walls in the parametric study were designed to explore the impact of varying levels of vertical and horizontal web reinforcement for different shear stress demand levels $\left(4.5,6.0\right.$, and $9.0 \sqrt{ } \boldsymbol{f}_{c}{ }^{\prime} \boldsymbol{A}_{c v}$ with $f^{\prime}{ }_{c}$ in psi). The primary interest in the study is evaluating the potential deformation and ductility gains for walls with moderate-to-high shear stress demands when designed in excess of the minimum web reinforcement ratios: (i) $\geq 0.0025$ for both vertical and horizontal steel, and (ii) $\boldsymbol{V}_{\boldsymbol{u}} / \boldsymbol{V}_{\boldsymbol{n}} \leq 0.75$ for horizontal steel. The resulting vertical and horizontal reinforcement ratios in the parametric wall study range from $0.25 \%$ to approximately $1.0 \%$; the upper bound was set so that designs did not significantly exceed the $0.25 \%$ minimum.

Each of the walls in the study were designed for two different boundary element length scenarios: the ACI 318-14 compliant length and a length approximately equal to the neutral axis depth, as was used by Whitman (2015) in the study described above. In all, 45 walls were designed. The resulting distribution of shear stress demands, shear demand-capacity ratios $\left(\boldsymbol{V}_{\boldsymbol{u}} / \boldsymbol{V}_{\boldsymbol{n}}\right)$ and horizontal reinforcement ratio in the web $\left(\boldsymbol{\rho}_{\boldsymbol{w e b}, \boldsymbol{h}}\right)$ as shown in Figure 12. All of these models had a boundary element length equal to the ACI 318-14 required length, the greater of

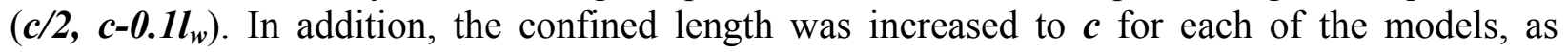
indicated in Figure 13. In all of the remaining figures, models with ACI-compliant boundary element lengths, $\boldsymbol{l}_{\boldsymbol{B} \boldsymbol{E}}$, will be indicated by a hollow marker and models with increased $\boldsymbol{l}_{\boldsymbol{B} \boldsymbol{E}}$ values will be indicated with filled markers. Although other parameters were varied, these two 
parameters had the largest influence on drift capacity and ductility. Additional information on the study can be found in Behrouzi (2016).

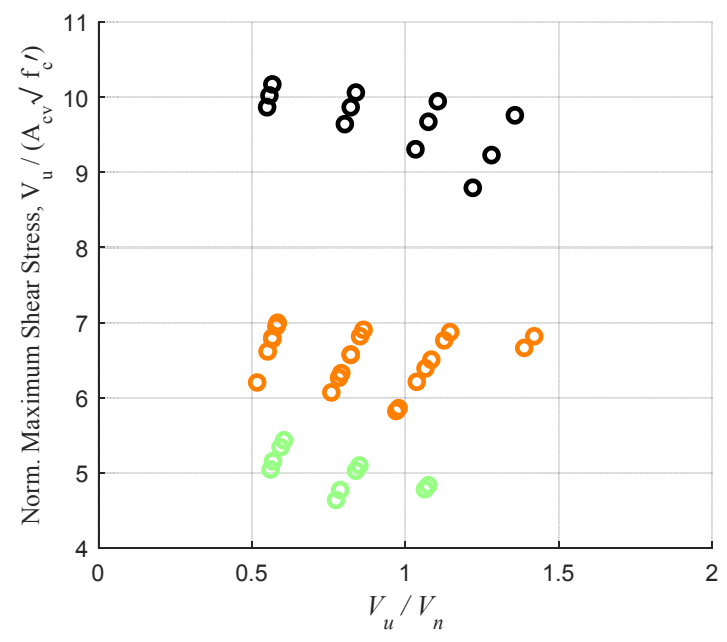

(a)

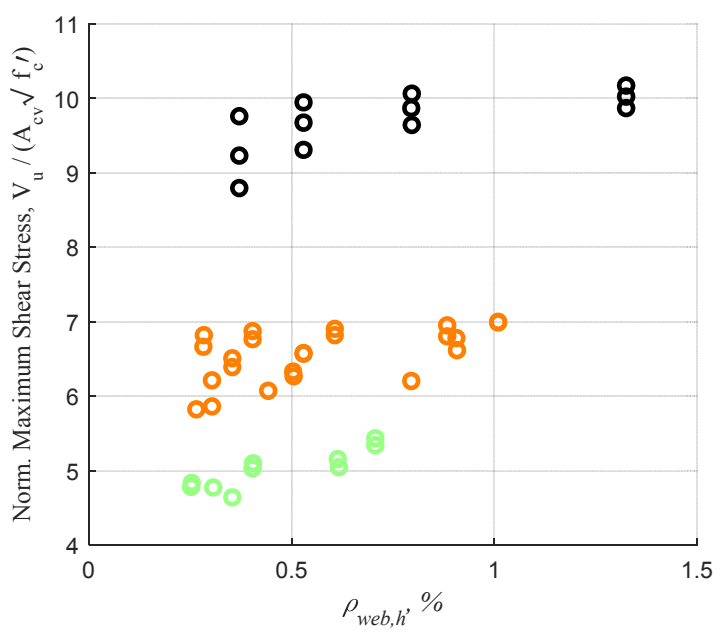

(b)

Figure 12. Variation in Shear Stress Demand as a Function of (a) Shear Demand-Capacity Ratio, and (b) Horizontal Web Reinforcement Ratio
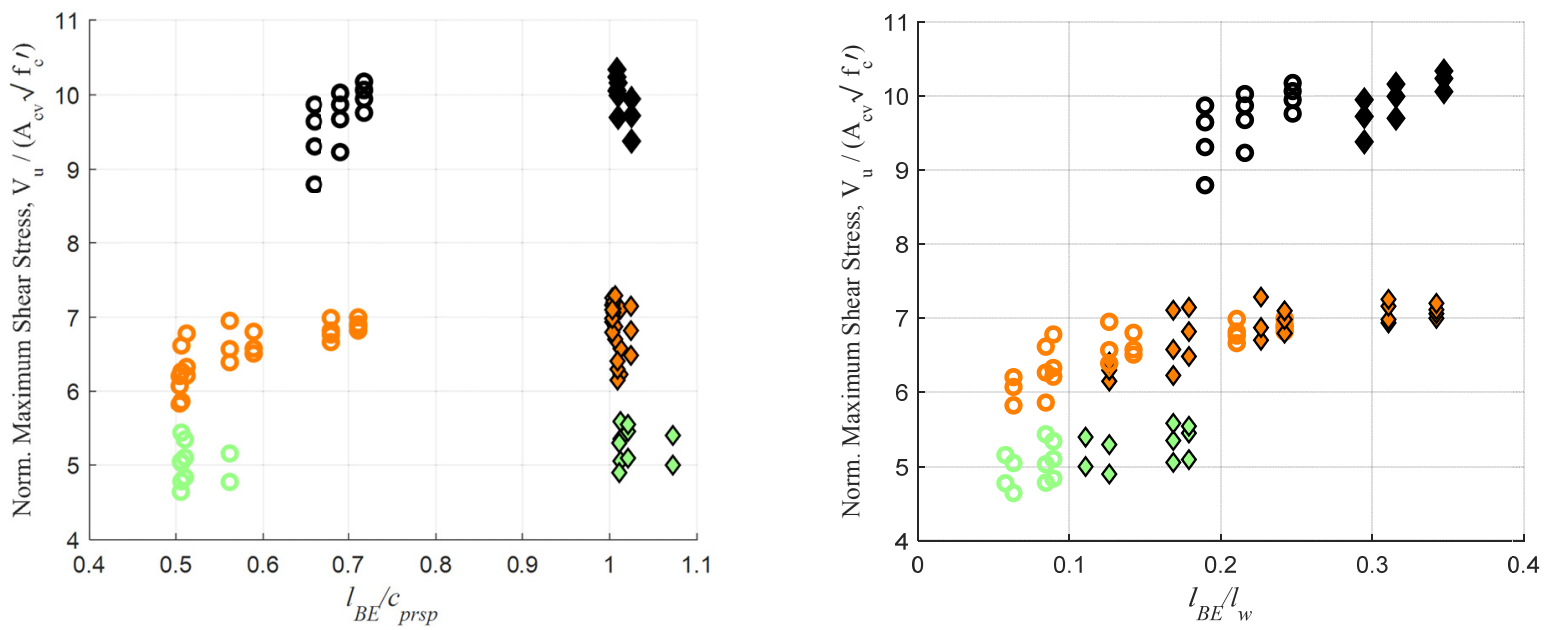

Figure 13. All Models Including Those with Confined Boundary Element Lengths Equal to the Neutral Axial Depth $\boldsymbol{c}$.

Shear stress demand, $\boldsymbol{V}_{\boldsymbol{u}} / \boldsymbol{}_{\boldsymbol{c}} \boldsymbol{A}_{\boldsymbol{c} \boldsymbol{v}}$, is the most influential parameter that was investigated in the parametric study. Figure 14 indicates that there is a strong negative correlation between shear stress and deformation/ductility. Walls with high shear stress demand $9.0 \sqrt{f_{c}} \boldsymbol{A}_{\boldsymbol{c}}$, exhibit a very narrow band of response as indicated by notably smaller standard deviation values compared to other walls. 

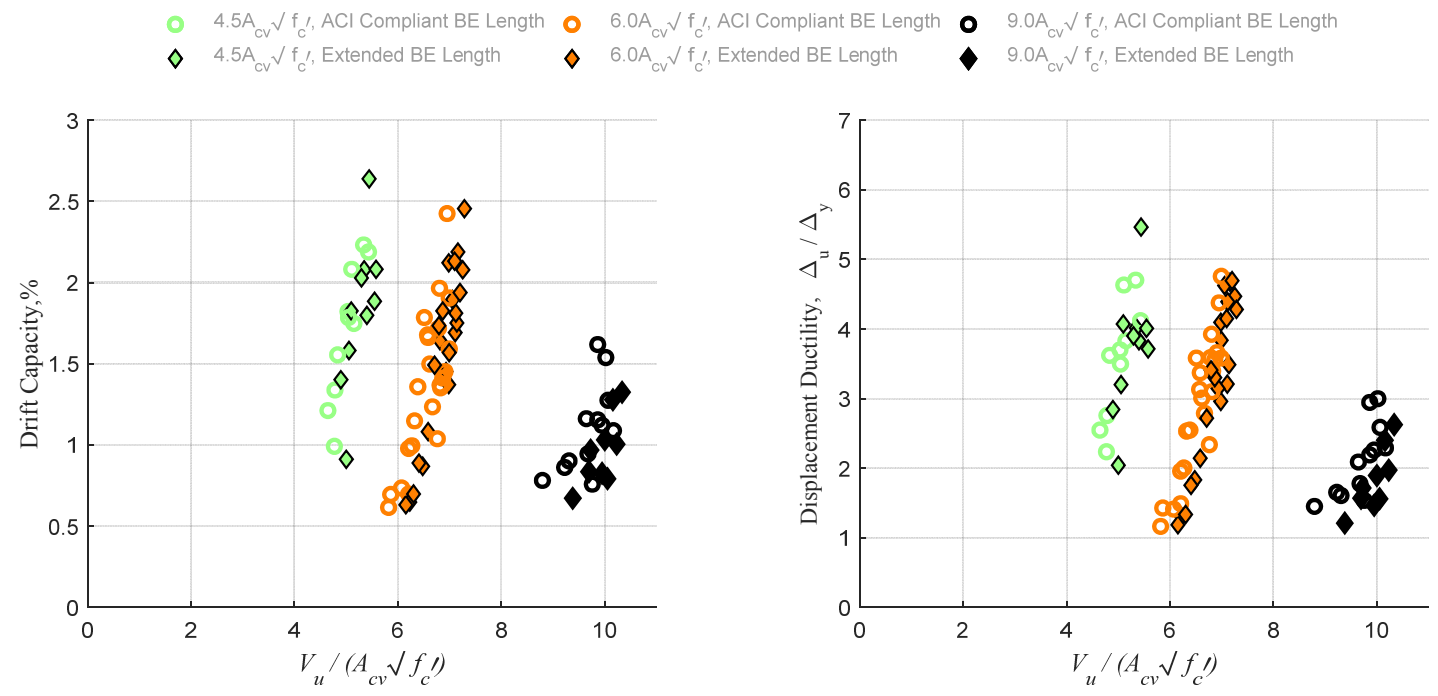

Figure 14. Impact of Shear Stress Demand on Drift Capacity and Displacement Ductility

The data in Figure 15 indicates that for ACI compliant walls there is a strong negative correlation between shear demand-to-capacity, $\boldsymbol{V}_{\boldsymbol{u}} / \boldsymbol{V}_{\boldsymbol{n}}$, and deformation/ductility. This negative correlation is not as pronounced for "extended" boundary element walls. These findings suggest that using a smaller $\boldsymbol{V}_{\boldsymbol{u}} / \boldsymbol{V}_{\boldsymbol{n}}$ value (or, a more conservative shear design) has benefits in terms of deformation/ductility for walls.

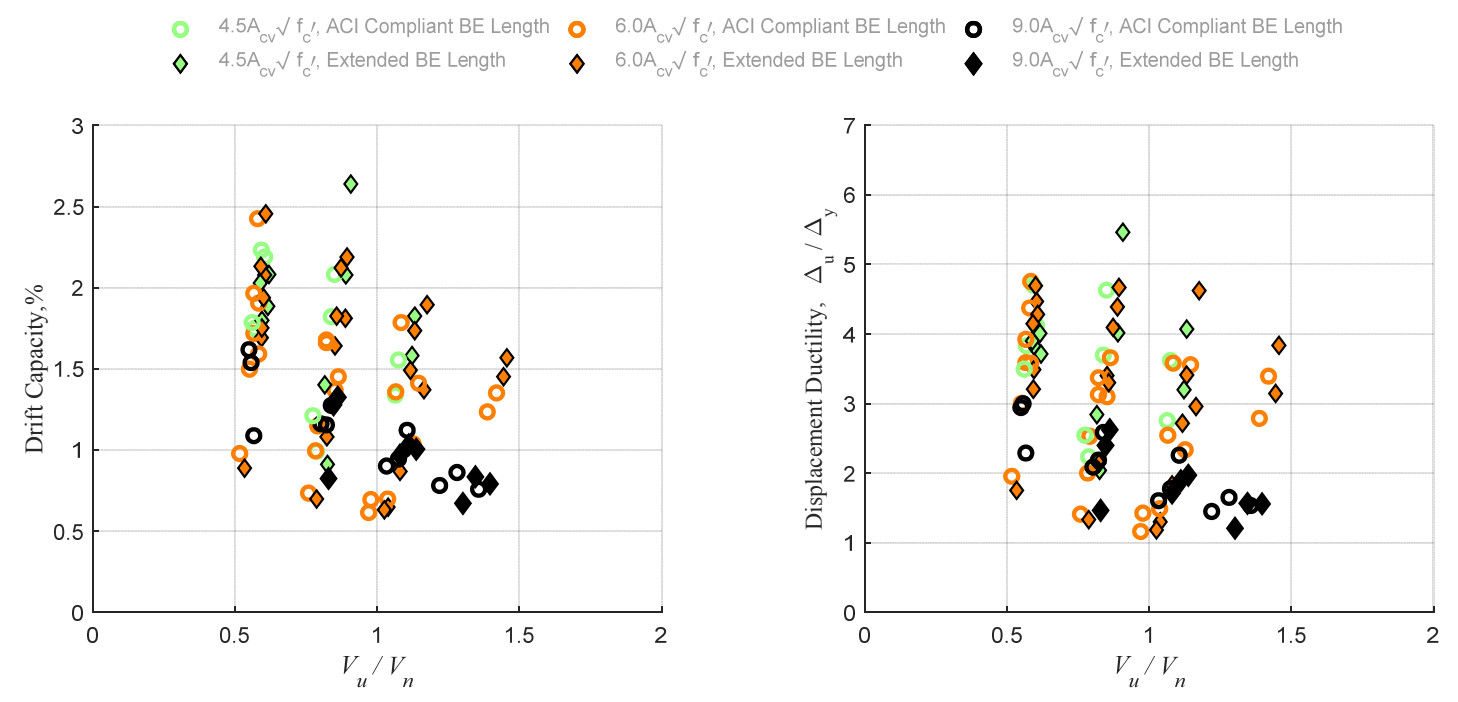

Figure 15. Impact of Shear Demand-Capacity Ratio on Drift Capacity and Displacement Ductility 


\section{DESIGN RECOMMENDATIONS}

Based on the research, the following design recommendations are made:

1. The boundary element confinement pattern, horizontal spacing and restraint pattern should follow the provisions for high-axial-stress columns, specifically ACI 318-14 Section 18.7.5.2, which requires every bar to be restrained, and a limit on $\boldsymbol{h}_{\boldsymbol{x}}$ of $8 \mathrm{in}$. It is of note that even at $\boldsymbol{M}_{\boldsymbol{n}}$, the axial stress in the boundary element will exceed $0.3 \boldsymbol{f}_{\boldsymbol{c}}$, which is the axial stress limit which triggers ACI 318-14.

2. The confined length should be increased with an increase in the shear stress demand as follows: $\boldsymbol{l}_{\boldsymbol{b e}}=\boldsymbol{c}\left(\boldsymbol{V}_{\boldsymbol{u}} /\left(8\left(\sqrt{\boldsymbol{f}^{\prime}}{ }_{\boldsymbol{c}} \boldsymbol{A}_{\boldsymbol{g}}\right)\right)\right)$ where $\boldsymbol{c}$ is the largest neutral axis depth calculated for the factored axial force and nominal moment strength consistent with $\boldsymbol{\delta}_{\boldsymbol{u}}$ and $4 \geq \boldsymbol{V}_{\boldsymbol{u}} /\left(\boldsymbol{V}^{\prime}{ }_{\boldsymbol{c}} \boldsymbol{A}_{\boldsymbol{g}}\right)$ $\leq 8$ which limits the boundary element length to values between $0.5 c$ and $c$.

3. For walls expected to achieve high ductility capacities, $\boldsymbol{V}_{\boldsymbol{u}} / \boldsymbol{V}_{\boldsymbol{n}}$ should be limited to 0.5

\section{CONCLUDING REMARKS}

The research studies described herein were undertaken to study and modify current design recommendations to improve the seismic performance of special $\mathrm{RC}$ walls; seismic performance is defined by both the damage sustained by the wall and its displacement ductility capacity. The studies used advanced experimental and analytical research approaches to investigate the parameters that were deemed to be most influential, specifically boundary element detailing, shear stress demand and web reinforcement. The results were compelling indicators that improving the boundary element detailing, by means of reduced spacing and restraint of every longitudinal bar and web reinforcement, improves the seismic performance by reducing undesired damage and increasing the wall deformability.

In addition, the analytical work revealed that the demands in the compressive region are a function of both the normal stresses, resulting from bending, and the shear stresses. The combination of the two stress states results in larger minimum principal stresses; these stresses are beyond that computed from a linear-strain analysis. As such, compressive damage can be sustained by the web in the case of larger shear stress demands. To mitigate this, a new expression for the confined length was developed; this length is a function of the normalized shear stress demand and is being considered for adoption by ACI $318 \mathrm{H}$, the subcommittee on seismic design.

\section{REFERENCES}

ACI. (2011). ACI 318-11: Building Code Requirements for Structural Concrete. Farmington Hills: American Concrete Institute.

ACI. (2014). ACI 318-14: Building Code Requirements for Structural Concrete. Farmington Hills, Michigan: American Concrete Institute.

ASCE. (2010). ASCE/SEI 7-10: Minimum Design Loads for Buildings and Other Structures. Reston, VA: American Society of Civil Engineers.

Behrouzi, A. (2016) Impact of Cross Section, Web Reinforcement and Load History on the Seismic Performance of Slender Concrete Walls. Ph.D Dissertation, Urbana: University of Illinois. 
Earthquake Engineering Research Institute (EERI). (2010). The Mw 8.8 Chile Earthquake of February 2010. EERI Earthquake Spectra Special Earthquake Report (June).

Lehman, D., Lowes, L., Pugh, J., and Whitman, Z. (2015) Nonlinear Analysis Methods for Flexural Seismic Reinforced Concrete Walls. Improving the Seismic Performance of Existing Buildings and Other Structures 2015: pp. 57-73. doi: 10.1061/9780784479728.006

Lowes, L. N., Lehman, D. E., Birely, A. C., Kuchma, D. A., Marley, K., \& Hart, C. H. (2012). Earthquake Response of Slender Planar Concrete Walls with Modern Detailing. Engineering Structures, 43, 31-47.

Mander, J. B., Priestley, M. N., \& Park, R. (1988). Observed Stress-Strain Behavior of Confined Concrete. Journal of Structural Engineering, 114(8), 1827-1849.

Mander, J. B., Priestley, M. N., \& Park, R. (1988). Theoretical Stress-Strain Model for Confined Concrete. Journal of Structural Engineering, 114(8), 1804-1826.

Massone, L. M., Polanco, P., \& Herrera, P. (2014). Experimental and Analytical Response of RC Wall Boundary Elements. Tenth U.S. National Conference on Earthquake Engineering. Anchorage.

Moehle (2010) Personal Communication

Network for Earthquake Engineering Simulation. (n.d.). NEEShub - The Chile Earthquake Database Group. Retrieved from https://nees/org/groups/chileearthquakedatabase

Oesterle, R., A. Aristizabal-Ochoa, J. Carpenter, H. Russell, and W. Corley. 1976. "Earthquake resistant structural walls - tests of isolated walls," Portland Cement Association/National Scienc Foundation, Washington, D.C., Tech. Rep. No. NSF/RA-760815.

Rodriguez, M., Botero, J., \& Villa, J. (1999). Cyclic Stress-Strain Behavior of Reinforcing Steel Including Effect of Buckling. Journal of Structural Engineering, 125(6), 605-612.

Tran, Thien Anh. 2012. "Experimental and Analytical Studies of Moderate Aspect Ratio Reinforced Concrete Structural Walls." Ph.D. dissertation, Los Angeles, CA: Dept. of Civil and Environmental Engineering, University of California, Los Angeles.

Vallenas, J., B. V.V., and E. Popov. 1979. "Hysteretic behavior of reinforced concrete structural walls," Earthquake Engineering Research Center, Berkeley, CA, Tech. Rep. No. UCB/EERC-79/20.

Wallace, John W., and John H. Thomsen IV. 1995. "Seismic Design of RC Structural Walls. Part II: Applications.” Journal of Structural Engineering 121 (1): 88-101. doi:10.1061/(ASCE)07339445(1995)121:1(88).

Welt, T. (2015). Detailing for Compression in Reinforced Concrete Wall Boundary Elements: Experiments, Simulations, and Design Recommendations Ph.D dissertation, Urbana: University of Illinois.

Welt, T., Massone, L., LaFave, J., Lehman, D., McCabe, S., \& Polanco, P. (n.d.). Confinement Behavior of Rectangular Concrete Prisms Simulating Wall Boundary Elements. Journal of Structural Engineering (accepted).

Whitman Z (2015). "Investigation of Seismic Failure Modes in Flexural Concrete Walls Using Finite Element Analysis." MS thesis, University of Washington, Seattle. 